\title{
La acción contenciosa del islam político durante la crisis hegemónica del Estado secular en Medio Oriente: los casos de Egipto e Irán ${ }^{1}$
}

\author{
The contentious action of political \\ Islam during the hegemonic crisis \\ of the secular State in the Middle \\ East: The cases of Egypt and Iran
}

\section{MOISÉS GARDUÑO GARCÍA*}

Resumen: El argumento central del texto es que las manifestaciones del islam político como un proyecto alternativo a la crisis del Estado secular en Medio Oriente tuvieron su origen no en la Revolución de Irán de 1979 sino en diversas acciones contenciosas lideradas por influyentes intelectuales islamistas desde los años cincuenta. Si bien la Revolución iraní de 1979 exportó el islamismo como un proyecto atractivo gracias a la difusión de una imagen redentora del ayatola Jomeini en el imaginario político popular de varios países de la zona, es en la crisis del nasserismo donde se encuentra la fusión de ideologías anticoloniales, antisionistas, nacionalistas e islamistas que mejor explica el desencanto popular del nacionalismo secular, por un lado,

Recepción: 25 de octubre de 2017. / Aceptación: 11 de julio de 2018.

* Universidad Nacional Autónoma de México, mgarduno@politicas.unam.mx

${ }^{1}$ Este artículo se realizó con respaldo del Programa de Apoyo a Proyectos de Investigación e Innovación Tecnológica (PAPIIT) a través del proyecto IN305119 Sectarismo y Justicia Social en el Medio Oriente del siglo XXI. 
y el fortalecimiento paulatino del islamismo, por el otro, al menos en algunas partes de Medio Oriente.

Palabras clave: acción contenciosa; crisis del Estado secular en Medio Oriente; islamismo; crisis de autoridad; cambio social.

Abstract: The central argument of this paper is that the political expressions of Islamism, as an alternative project to the crisis of the secular State in the Middle East, emerged not from the 1979 Iranian Revolution but from diverse contentious actions led by influential Islamist intellectuals since the 1950s. Although certainly the 1979 Iranian Revolution exported Islamism as an attractive project thanks to the diffusion of an heroic image of Ayatollah Khomeini in the popular imaginary of several countries in the region, the crisis of Nasserism is the place from where we can trace the fusion of anticolonial, anti-Zionist, nationalist and Islamist ideologies, explaining the popular disenchantment of secular nationalism on the one hand, and the strengthening of Islamism, on the other, at least in some parts of the Middle East.

Keywords: contentious action; crisis of secular state in the Middle East; Islamism; authority crisis; social change.

El argumento central del texto defiende que no hay que esperar hasta el triunfo de la Revolución de Irán de 1979 para ver las manifestaciones del islam político como un proyecto alternativo a la crisis del Estado secular en Medio Oriente, sino que se pueden rastrear a través de diversas acciones contenciosas lideradas por influyentes grupos e intelectuales islamistas desde los años cincuenta.

Si bien la Revolución iraní de 1979 exportó el islamismo como un proyecto atractivo gracias a la difusión de una imagen redentora del ayatola Jomeini en el imaginario político popular de varios países de la zona, es en la crisis del nasserismo donde se encuentra la fusión de ideologías anticoloniales, antisionistas, nacionalistas e islamistas que mejor explica el desencanto popular del nacionalismo secular, por un lado, y el fortalecimiento paulatino del islam político en varias partes del Medio Oriente, por el otro. Tomando como punto de partida lo ocu- 
rrido en Egipto antes de la derrota de 1967 y en Irán antes de la revolución de 1979, este texto conduce al entendimiento de los movimientos islamistas no como grupos reactivos y meramente religiosos, sino como organizaciones que utilizaron el islam como herramienta de movilización política y que aprovecharon la crisis de autoridad en sus respectivos escenarios para construir nuevos espacios de articulación y transgresión al orden dominante, que fue ganando apoyo popular en un contexto marcado por la Guerra Fría.

Mediante evidencias se intentará demostrar que, en el caso egipcio, la intervención de fuerzas externas y la lucha interna dentro de la Hermandad Musulmana fueron los obstáculos más visibles que impidieron una contracción hegemónica que condujera al cambio en el orden político nacional después de 1967, mientras que, en el caso iraní, la intervención extranjera a través de la guerra Irán-Iraq tuvo efectos diferentes porque los líderes y los intelectuales del nuevo régimen la canalizaron para terminar con las divisiones internas de su movimiento e implementar una purga política, por un lado, y para ganar legitimidad en el proceso de institucionalización de un nuevo sistema de gobierno, por el otro. Aunque el desenlace de cada movilización fue distinto, merece la pena comparar el método utilizado por los actores islamistas subalternos no sólo para estudiar su reacción frente al Estado secular, sino también para analizar cómo propusieron un escenario social, ideológico y político alternativo a la autoridad dominante de su época.

\section{Apuntes teóricos}

De acuerdo con Antonio Gramsci, la hegemonía no es sólo un instrumento para gobernar, sino también la manifestación de la orientación del poder en la vida cotidiana de las clases subalternas. Aunque Gramsci escribió muy poco sobre el denominado mundo araboislámico, ${ }^{2}$ sus aportaciones son valiosas para el

${ }^{2}$ Gramsci reconoció la contribución histórica de las civilizaciones musulmana y árabe en sus artículos periodísticos, en sus cartas antes de ser encarcelado y en los mismos Cuadernos de la cárcel. El mundo islámico de su época era mayormente rural, con masas fuertemente influidas por la religión, análogas en cierta forma a Italia, cuya 
estudio del cambio sociopolítico en la región porque ayudan a entender la expresión de la hegemonía en instituciones como las escuelas, las asociaciones religiosas, los museos, los sindicatos, los partidos políticos y los medios de comunicación, en lo que Marx también llamó "los medios de producción ideológica”, y en la forma en la que éstos suelen orientar los actos políticos, ideológicos y culturales de las personas hacia una dirección determinada (Gramsci, 2009, p. 311). En este sentido, si bien los postulados de Gramsci invitaron al estudio de la contrahegemonía como el proceso por el cual el prestigio del poderoso y su maquinaria se pone en tela de juicio, es menester reflexionar, desde una mirada que revisa la teoría gramsciana, que esto no se trata sólo de un acto de estricta resistencia o de meras reacciones directas, puras y duras, al grupo en el poder, sino que puede pensarse también como un ejercicio de constante irrupción y desgaste, un fenómeno activo, transgresivo y propositivo, que actúa mediante el aprovechamiento de las debilidades de "los de arriba" para cambiar el orden a través de acciones contenciosas. ${ }^{3}$

Uno de los intelectuales que ha estudiado los postulados de Gramsci para aplicarlos al análisis de la protesta como un ejercicio activo en Oriente Medio es John Chalcraft (2016, p. 31), especialista en historia crítica de los movimientos populares en la región y quien retomó el concepto de acción contenciosa o movilización contenciosa (Tarrow, 2011; Tilly y Tarrow, 2015) para entender la formación de sujetos colectivos

\footnotetext{
economía todavía estaba orientada en gran parte hacia un campesinado entre el cual las autoridades religiosas desempeñaban un papel importante (y muy reaccionario). Además de factores como el nexo entre política y religión, Gramsci también analizaba, sin decirlo de forma explícita, la conmoción causada por la desintegración y el desmembramiento del Imperio otomano y las rivalidades interimperialistas por el botín y la construcción de nuevos Estados. Llama la atención sobre las primeras posturas anticoloniales que se adoptan entre los líderes tradicionales y reconoce la base para la formación de movimientos populares. Lo que emerge es una imagen de hegemonías conflictivas que involucran principalmente la religión, la clase, la tribu, la ambivalencia política de muchos líderes religiosos y un nacionalismo floreciente contrapuesto a los reclamos supranacionales de la religión. Véase Boothman, 2012.

${ }^{3} \mathrm{La}$ acción contenciosa es un concepto acuñado en la academia estadounidense por un grupo de profesores interesados en los movimientos y las movilizaciones sociales del siglo xxi (McAdam, Tarrow y Tilly, 2008, p. 387). De acuerdo con su definición, se trata de "una amplia gama de movilizaciones en el campo formal e informal que vincula la esfera local con la global en un contexto dado" (Tarrow, 2010, p. 25).
} 
y de nuevos liderazgos en términos de articulación de sectores emergentes más que en la reacción de sectores dispersos. Por acción contenciosa el autor entiende un proceso de articulación y rearticulación de ideas y prácticas políticas que permite analizar el cambio de la voluntad colectiva y que se visibiliza en el campo de la sociedad civil mediante lo que Gramsci $(2012$, p. 12) denominaba "la guerra de trincheras" (guerra di posizione).

Es importante notar que estas prácticas de desectorización implican el estudio de las formas en que diversas fuerzas sociales que nacen y se desarrollan en la esfera pública se aglutinan en torno a demandas y objetivos específicos y producen un nuevo campo de lo político donde se gradúan nuevos liderazgos de corte moral e intelectual, así como otras formas de solidaridad, conexiones y canales de articulación de intereses que pueden provocar una crisis de autoridad o una contracción hegemónica (en términos gramscianos) si los nuevos sujetos colectivos trabajan por los intereses de los subalternos y no por los del régimen (Chalcraft y Noorani, 2007, p. 4; Buttigieg, 1987, p. 31).4

Esta crisis de autoridad, provocada por el surgimiento de nuevos bloques que superan su división, puede ir acompañada del riesgo de ser intervenida por élites extranjeras, algo muy común en la historia moderna del Medio Oriente. ${ }^{5}$ Así, cuando

${ }^{4} \mathrm{La}$ tensión entre la élite en el poder y las acciones contenciosas de los subalternos ha sido conceptualizada por John Chalcraft (2016, p. 36) como contracción begemónica, idea muy parecida a la de crisis de autoridad o crisis de hegemonía de Gramsci (2012, p. 124), la cual se produce cuando se pierde el equilibrio entre la coerción y el consenso, pues "una combinación de ambos era la mejor técnica para mantener el poder". Dicho de otra forma, cuando el Estado ya no es capaz de remplazar el consenso con la coerción, entonces es posible una agitación de la expansión hegemónica donde ni las formas más sutiles de gobierno, ni las medidas de cooptación, ni las formas más represoras funcionan como se espera.

${ }^{5}$ En el caso particular de Medio Oriente, se ha demostrado a través de la historia que las contracciones hegemónicas han ido acompañadas de la intromisión extranjera. Los siguientes ejemplos pueden ser evidencia para este argumento: Gran Bretaña ocupó Egipto en el marco del movimiento Urabi de 1881-1882; Francia intervino en Líbano en medio de las protestas de Monte Líbano de 1821, 1840 y 1858-1860; Francia intervino ante las revueltas anticoloniales en Siria en 1925-1927; Gran Bretaña y Francia también intervinieron en las revueltas de Yemen del Sur en 1967 y de Argelia en 1962; Israel y Siria intervinieron en la guerra civil de Líbano en 1975 y Estados Unidos y Gran Bretaña lo hicieron en Irán mediante el golpe de 1953 en contra de Mohammed Mossadeq. Más recientemente es preciso recordar la intervención de la OTAN en Libia en medio de las revueltas populares de 2011, tal como Arabia Saudí intervino en las revueltas de Bahréin y Yemen y, por supuesto, el caso de la intervención en Siria por 
el surgimiento de nuevos sujetos colectivos en actos de protesta coincide con la presión del factor externo, la élite en el poder que enfrenta la crisis de autoridad intentará resolverla mediante un alto grado de pragmatismo y negociación, aunque su éxito no siempre dependerá de dicha capacidad, sino de factores ajenos a su control, entre los que se encuentra el éxito de las acciones colectivas de los grupos que enfrenta, la interacción de estos grupos con otras comunidades similares en el extranjero, o bien el grado de negociación con élites trasnacionales que buscarán expandir su influencia hegemónica a expensas de dicha coyuntura.

Por lo tanto, la justificación ideológica de la superestructura política con la cual se incorporan sujetos al poder mediante violencia, chantaje, clientelismo o simplemente por convencimiento ideológico es un fenómeno simultáneo a la construcción de una política contenciosa con repertorios, armados y no armados, como rebeliones obreras, movimientos sociales, desobediencia estudiantil, huelgas, entre otros, los cuales suelen ir acompañados de sólidos sustentos intelectuales que pueden ser ideológicos o no, pero que cuentan con características "ideacionales" en el sentido de que siempre hay normas, creencias y actitudes con las cuales la gente se guiará para alcanzar órdenes posibles y no sólo para reaccionar al orden establecido.

Considerando lo anterior, conviene mencionar que los actores que producen acciones contenciosas necesitan recursos, alianzas y capacidades diversas. Espacios liberados en universidades, el espacio de las prisiones, salones de congregación, seminarios, madrasas, mezquitas, así como el dinero de aliados, comerciantes, terratenientes, simpatizantes o de diásporas, que constituye la base del capital intelectual y de la orientación de las guerrillas en caso de que se trate de movimientos armados. Son formas de organización del cuerpo y una relación con el territorio donde interactúan para establecer estrategias de contención, algo muy importante en el pensamiento de Gramsci (2012, p. 210).

parte de Estados Unidos, Rusia y otros actores regionales desde 2011 y 2015 respectivamente. 
Ahora bien, a diferencia de lo hecho por Tarrow (2011) o Tilly y Tarrow (2015), vale la pena no discutir el asunto de la democratización como horizonte de la acción contenciosa. La razón estriba en que las teorías que suelen utilizar este enfoque lo hacen en contextos donde la democracia parece ser el destino último de todo proceso de liberación, o al menos un componente central para medir sus logros (Giugni, McAdam y Tilly, 1998, p. 57; Tilly y Tarrow, 2015, p. 232). Por tal motivo, para efectos de este texto se parte de la idea de que no todo proceso de liberación implica un proceso de democratización, aunque todo proceso de democratización implique cierto grado de liberalización, al menos en el campo de la expansión del espacio público y del reconocimiento y protección de libertades civiles y políticas (Sierra, 2001, p. 16).

La historia del Medio Oriente moderno ha observado una amplia participación de grupos subalternos en la esfera pública, así como de intelectuales orgánicos que han generado los contenidos contrahegemónicos con los cuales se ha disputado el espacio del poder simbólico. Esta perspectiva pone en tela de juicio las posturas orientalistas que afirman que en el Medio Oriente, en general, y con los árabes y los musulmanes en particular, "no se puede hablar de una sociedad civil" porque "en esta región, cuando la gente sale a las calles no hace manifestaciones sino insurrecciones" (Pipes, 1995) y que "la sociedad no se manifiesta racionalmente, sino que hace llamamientos de ira o rabia" (Lewis, 1990). 6

No obstante lo anterior, investigadores como Marshall Hodgson (2009), Albert Hourani (2013), Edward Said (1981) y Hamid Dabashi (2017), entre muchos otros, han encontrado suficientes argumentos, con sus respectivas evidencias, para sostener que en la región, tal como ocurre en otras partes del mundo, se puede hablar de una sociedad civil como un espacio cada vez más dotado de contenidos sobre formas y estrategias de lucha y crítica contra los autoritarismos, los extremismos y otras formas de dominación en diferentes niveles que van des-

${ }^{6}$ Hay otras más radicales que, en pocas palabras, ven a Medio Oriente como una región que presenta serios obstáculos no sólo para echar a andar un proceso de liberación, sino también para la generación de una civilización entera. Véase Huntington, 1993, p. 25. 
de el político y el económico hasta el discursivo. Esto se ha apreciado en numerosos ejemplos históricos, como las luchas contra Napoleón ante la invasión de Egipto de 1798, la revolución iraní de 1906, el despojo catastrófico de Palestina por parte de Israel en 1948, y en muchos otros escenarios en pleno siglo XXI, que van desde el movimiento antiguerra en 2003 hasta los levantamientos populares de 2011, donde el papel de nuevos liderazgos, teorías de emancipación, movimientos armados y diásporas politizadas han ido moldeando una sociedad civil cada vez más sólida en la región, generación tras generación.

Aunado a esto, como un espacio donde los sujetos subalternos suelen interesarse cada vez más en asuntos relacionados con otras luchas en los ámbitos local, regional y global, es preciso enfatizar que el alcance de la sociedad civil no es meramente local y que se extiende a ámbitos trasnacionales no sólo por las diásporas que conforman mecanismos propios de información y redes de solidaridad, sino también por la afinidad y la resonancia que hay con causas de diversos sujetos colectivos que viven en geografías distantes (Dabashi, 2011, p. 230). El caso del periodo que se convoca en este texto, denominado fechas limites (Quintana, 1986, p. 21), constituye una evidencia de lo anterior y toma como eje argumentativo el repertorio de movilización islamista en dos países en particular, Egipto e Irán.

\section{Egipto e Irán durante la crisis hegemónica del Estado secular en Medio Oriente}

La crisis del Estado secular en Medio Oriente corresponde a la crisis hegemónica de un discurso modernizador y supuestamente de vanguardia en el que los proyectos de los denominados "nacionalistas radicales" perdieron su autoridad y su influencia popular, por una parte, al fracasar en la mejora de la situación de los más desfavorecidos y, por la otra, al militarizar el orden social en lo que Santiago Quintana (1986, p. 24) denominó "una estrategia de desmovilización de las masas".

En esta crisis, el Egipto de Nasser y el Irán de Mohammad Reza Pahlevi echaron a andar estrategias similares de monopolio de los canales regulares del discurso político, como la prensa, 
la radio y la televisión, así como estrategias sistematizadas de represión contra grupos marxistas, islamistas y anarquistas que no sólo reaccionaron a dicho poder, sino que plantearon un discurso y una praxis política alternativa al graduar nuevos liderazgos políticos, sociales e intelectuales.

A pesar de las enormes diferencias sociales y culturales, había paralelismos en ambos gobiernos en términos de desigualdad, pobreza y propaganda. Si bien a principios de los años sesenta todos los países de la región tenían tasas de analfabetismo juvenil superiores a 50\%, en Egipto e Irán llegaban hasta 75 y $68 \%$, respectivamente, cuando eran los únicos países de la región que habían abierto universidades modernas casi medio siglo antes (Amin, 1980, p. 62; Abrahamian, 2008, p. 142). A pesar de que Egipto era una república con una alianza táctica con Moscú, e Irán una monarquía aliada de Washington, ambos países tenían menos de $1 \%$ de su población enrolada en las universidades públicas y sólo una pequeña minoría disfrutaba del supuesto modernismo de la época (The World Bank, 1960).

Con una densidad demográfica similar, la mayoría de la población de ambos países se encontraba empobrecida y vivía en zonas rurales, lo que favorecía enormes éxodos a las dos ciudades ícono de la modernización regional, esto es, El Cairo y Teherán. A principios de los años cincuenta, $44 \%$ de las familias rurales en Egipto no poseía tierra alguna y tan sólo $0.4 \%$ (cerca de dos mil familias) poseía 34\% de la tierra cultivable del país. Tras la reforma agraria de Nasser en 1952, sólo hubo un periodo en el que las cosas cambiaron (de 1961 a 1964), pero luego de 1966 la inequidad persistió y la pobreza se expandió incluso dentro de las mismas ciudades, como lo representó el barrio de Giza en El Cairo y el barrio de Darvazeh Gar al sur de Teherán (Waterbury, 2016, p. 209). El caso de Irán fue muy similar, con $45 \%$ de la población viviendo empobrecida en zonas rurales mientras $0.1 \%$ controlaba los principales espacios de poder, por lo que, en palabras del historiador iraní Ervand Abrahamian (2008, p. 140), "Irán pudo haber sido considerado como el caso con la mayor inequidad salarial del mal llamado Tercer Mundo y uno de los peores a nivel global".

\footnotetext{
${ }^{7}$ Excepto Líbano y Jordania, que tenían tasas de 10 y $38 \%$ respectivamente.
} 
En ambas naciones, las clases acomodadas comenzaron a vivir en suburbios que se acondicionaron específicamente para ellas. En el caso de Egipto, el régimen construyó Medinat Nasr (conocida como Nasr City), una ciudad especial para acomodar a la clase gobernante y pensada como un espacio que podría ser la nueva capital del país. Concebida para expandir la hegemonía y la legitimidad del régimen, tal como otros proyectos (entre ellos la presa de Aswan), esta ciudad fue anunciada, de acuerdo con sus folletos en 1958, como la "Ciudad de la Revolución", y se componía de "superbloques con apartamentos demasiado caros para los pobres en aras de abastecer a la nueva clase media" (Elshahed, 2015). ${ }^{8}$ En el caso de Irán se debe pensar en Niavaran, al norte de Teherán, una zona de la ciudad que era como cualquier capital de Europa occidental y que albergaba los principales sitios gubernamentales, embajadas, palacios reales, empresas trasnacionales, viviendas para extranjeros, el hotel Hilton (inaugurado en 1962 y que hoy se conoce como Esteghlal) y los mejores servicios de seguridad social para no menos de $20 \%$ de la sociedad tehraní (Abrahamian, 2008, p. 141).

Lo que resulta interesante es que, para finales de los años sesenta, en ambos países se experimentó un fenómeno de cierta libertad y derechos para las mujeres, aunque dicho discurso hegemónico coincidió con prácticas represivas contra la libertad de expresión, la libertad de prensa, la libertad de pensamiento y la libertad política, que se materializaron en el poder de la policía secreta de ambos países, la Mabahith Amn El Dawla egipcia y la SAVAK iraní, creadas gracias a la ayuda de los servicios de inteligencia soviéticos y estadounidenses respectivamente (Kahana y Suwahed, 2009, Introducción).

A pesar de que el presidente egipcio gozó de una popularidad enorme a mediados de los años cincuenta, Nasser no pu-

${ }^{8}$ El plan urbano inicial y los diseños arquitectónicos fueron elaborados por el arquitecto y planificador Sayed Karim. El folleto del proyecto contenía texto en árabe e inglés y fue diseñado para atraer a residentes educados de clase media y alta a quienes se aseguró que la nueva ciudad sería "planificada de acuerdo con las últimas teorías de planificación urbana”. Se planearon nuevos edificios administrativos (y algunos construidos) para albergar nuevos ministerios y reubicar a otros del área del centro de la ciudad. Se suponía que era una ciudad moderna que reflejaba el progreso del nuevo régimen. 
do basar la estabilidad de su gobierno sólo en su carisma y fortaleció sus aparatos de seguridad en medio de un contexto regional agitado por la ola de agrupaciones comunistas, fascistas, anarquistas e islamistas que Egipto y otros países de la región experimentaron (Wickham, 2003, p. 23). De hecho, habría que pensar que Nasser y sus asesores anticiparon muy bien el activismo de la oposición y lanzaron un programa educativo popular que basó sus contenidos en la producción de sentimientos de lealtad, legitimidad y consenso hacia el líder, lo que condujo a la cooptación del movimiento obrero para su proyecto durante la década de 1950 y principios de la de 1960 bajo el lema "disciplina, unidad y trabajo".

En el caso del shah pasó algo muy similar. Después del fracaso del Frente Nacional de Irán en derrocar al monarca a través de un programa de nacionalización petrolera con el cual, al igual que Nasser, intentó ganar legitimidad popular a través de un discurso antiinjerencista, la influencia del golpe de Estado perpetrado por la Agencia Central de Inteligencia (CIA) en 1953, mediante la conocida Operación Ajax, fue nodal para el restablecimiento del shah, con lo que se inició la restructuración de los servicios de inteligencia para asegurarse de no experimentar una nueva crisis de autoridad que pusiera en riesgo el control hegemónico, político, social y económico del país (De Bellaigue, 2013, p. 299).

Ambos escenarios se deben contextualizar en la crisis del discurso secular y modernizador de los dirigentes de ambos países, que se evidenció con los primeros fracasos del panarabismo en Egipto y su relación con el factor externo. Las pruebas de este argumento radican en la negativa de Iraq a unirse a la República Árabe Unida, el fiasco de la Federación Árabe entre Jordania e Iraq, el eventual colapso de ambos proyectos y la fallida campaña militar de Egipto en Yemen en 1962. Estos sucesos muestran que el panarabismo, en sus múltiples formas, ya se encontraba seriamente limitado antes de la derrota de Nasser en 1967, la cual sólo visibilizó dichas fracturas, al menos en la esfera pública trasnacional (Sorby, 2004, p. 3; Barnes, 2014; Azaola, 2008, p. 71). ${ }^{9}$

${ }^{9}$ La Federación Árabe entre Iraq y Jordania fue un proyecto constituido en 
En el caso de las estructuras políticas y económicas de la monarquía Pahlevi, también entraron en crisis, no sólo por la crítica a su política exterior tan cercana a Estados Unidos e Israel, sino también por las consecuencias económicas y sociales que la Revolución blanca había provocado en el sector del trigo, además del daño a los bolsillos de buena parte de la élite bazarí, una de las más importantes del país, que veía con distancia la saturación de las calles de Teherán con empresas extranjeras como Coca-Cola y Pepsi, las cuales generaron un rechazo generalizado en otros sectores de la sociedad que, finalmente, la llevaría a articular canales de entendimiento con guerrillas marxistas e islamistas en años subsecuentes. ${ }^{10}$ Lo anterior hay que ligarlo a la ocupación iraní de tres islas importantes en el golfo Pérsico ante la salida de los británicos: Gran Tunb, Menor Tunb y Abu Musa, como un intento de expansión hegemónica que el shah buscaba en el exterior debido a la situación que, en el plano doméstico, se agravaba cada vez más.

\section{El islam político como acción contenciosa}

Los datos anteriores ayudan a entender la labor contrahegemónica del islam político, el cual, pese a sus diferencias en métodos y técnicas, tiene el objetivo común de encontrar la unidad de la umma (comunidad islámica) como el eje que restaure el orden social perdido. Esta corriente se entiende mejor gracias al análisis de algunos intelectuales como Ali Shariati o Yusuf al Qaradawi, que lograron articular un pensamiento emancipador de corte antiimperialista y antisionista con las necesidades sociales y económicas de todas las clases de la sociedad, en particular de

el periodo que abarca de febrero a julio de 1958 y que en su momento consideró la unión con Siria.

${ }^{10}$ Enqelab-e Sefid es el nombre del proceso económico por medio del cual el gobierno del shah intentó consolidar su dominio del Estado a través de un discurso nacionalista que conciliaba el "modernismo" con la "tradición" siguiendo la fórmula egipcia experimentada por Nașer desde 1956 hasta su derrota militar ante Israel en la guerra de los Seis Días. Este tipo de reformas, sin embargo, también se llevaron a cabo debido a las presiones del exterior para cubrir las deudas pendientes de Irán con el Banco Mundial, el cual le había otorgado un préstamo cercano a los 650 millones de dólares en 1948 y que se esperaba cubrir con la renta petrolera en un tiempo no mayor a siete años, ya que se veía dicho recurso como fuente de ingresos. 
los más desfavorecidos, al encontrar en su lenguaje contestatario una opción para resolver los problemas causados por el mal gobierno de las llamadas al mubadi' al mustawarda (doctrinas importadas). Si bien los "desheredados" fueron los que nutrieron los movimientos islamistas de estos años, los intelectuales los lideraron y los encauzaron hacia un objetivo político de cambio social y reordenamiento moral (Quintana, 1986, p. 24).

En principio, este proceso de irrupción puede entenderse como una etapa de continuidad intelectual que operó desde la clandestinidad, e incluso desde la misma prisión, lugar a veces considerado como una oportunidad para reexaminar algunos conceptos o postulados previos elaborados para la lucha anticolonial (Butko, 2004, pp. 141-162) ${ }^{11}$ Es importante subrayar lo anterior porque los pensadores que reflexionaron durante el agotamiento del modelo secular cobraron un matiz combativo que se combinó con perspectivas de índole jurídica y filosófica más que de carácter estrictamente religioso (Rafiabadi, 2007, p. 873; Kurzman, 2002, p. 389). ${ }^{12}$ Una clave para entender este proceso es que el grueso de estos intelectuales no se había formado en seminarios o escuelas puramente religiosas, sino en universidades modernas, con una cercanía a los referentes culturales de Occidente, cuestión por la cual los resultados de sus publicaciones, sermones y manifiestos se leyeron más como invitaciones ideológicas a la movilización política que como expresiones de una religiosidad popular (Adams, 1971; Bowering, 2012, p. 656; Saleh, 2016, p. 336). ${ }^{13}$

Por tal motivo, la visión de muchos intelectuales islamistas de la época fue la de un islam diferente que superara la concep-

${ }^{11}$ Entre estos intelectuales se encontraban Abel Rahman al Kawakibi, Yamal al Din al Afgani, Muhammad Abdu y Rashid Ridda, entre los más sobresalientes.

${ }^{12} \mathrm{La}$ fundación de los grupos que influyeron en pensadores de estos momentos se conoció en primera instancia como el movimiento salafiyya [lo que precede o movimiento de los predecesores]. Un ejemplo de esto lo constituye la revista $A l$ Urwa Al Wutha [El lazo indisoluble], publicada por Yamal al Din al Afgani y Mohammad Abdu en París en 1884.

${ }^{13}$ Las primeras organizaciones que resultaron de dicha producción intelectual fueron Al Ijuan al Muslimin [la Hermandad Musulmana], creada en 1928 en Egipto, y Al Jamaat al islami [Asociación Islámica], con origen en la India británica (después Pakistán) en 1941. Entre los intelectuales que se refieren a este proceso como resurgimiento islamista se encuentra Al Anani (2016, p. 199). Para una historia de Pakistán se recomienda Haqqani (2015, p. 415). 
ción religiosa y reduccionista con la que se le representaba desde el ámbito secular, para convertirse en un instrumento crítico de la utopía del nacionalismo secular, desde el kemalismo, el socialismo árabe, la monarquía Pahlevi, el baa'thismo sirioiraquí, hasta el sionismo israelí, esto para dar la bienvenida a un proyecto no revivalista ni fundamentalista, sino constructor de una sociedad justa mediante el uso de conceptos clave como tawhid (integración), iyma' (consenso) y shura (asamblea o consulta), entre otros, de tal manera que el mensaje intelectual fuera entendido por las masas como un proyecto por la justicia económica, social y moral en medio de un contexto de crisis, violencia e incertidumbre como el que se vivía en el Medio Oriente de los años sesenta y setenta.

Aunque es compatible con la mayor parte de las máximas del capitalismo, el islam político incluye la búsqueda de un sistema económico que garantice un nivel elevado de prosperidad social y una relativa igualdad en la provisión de necesidades básicas de la comunidad (Quintana, 1984, p. 30). Muchos movimientos de esta época, así como los de principios del siglo XIX, fueron influidos por el pensamiento de Ibn Taymiya (1263-1328) y Muhammad Abdel Wahab (1702-1791), en el sentido de la necesidad de retomar algunos preceptos islámicos para llevarlos a la práctica y desafiar al Estado secular para superar su agotamiento como utopía de progreso, tal como estos pensadores lo habían hecho en sus respectivos contextos (Saleh, 2006, p. 28).

De acuerdo con Quintana (1986, p. 37), la noción del islam como vehículo contestatario tanto de "desheredados" como de "frustrados" que veían empobrecer cada vez más sus países tan ricos en recursos, lanzó fuertes interrogantes a las acciones contenciosas de grupos marxistas y de la denominada izquierda árabe para disputarse la base social del sector obrero y la élite comercial, que eran estratégicas para todos los actores implicados. Es muy interesante observar cómo la clase media de los bazaríes, los comerciantes, los estudiantes universitarios y otros profesionales comenzó a seguir (y en ocasiones a financiar) movimientos islamistas en lugar de orientarse por las izquierdas en el ámbito urbano, ya que el islamismo se presentó como una corriente crítica y propositiva al hablar de la necesidad de 
construir un Estado islámico como primer horizonte ante la corrupción que criticaba. En el ámbito rural, en su mayor parte, fue el islamismo, y no el marxismo ni otras agrupaciones seculares, el que logró articular sus intereses no sólo con las preocupaciones de las personas del campo, sino también con las del espacio rural que habían migrado a la ciudad.

Mientras la derrota del 67 en Egipto y la Revolución de 1979 fueron dos coyunturas críticas para el andamiaje de los respectivos islamismos de estos países, hay que tratar este asunto como un proceso simultáneo a las fracturas de las burguesías nacionales y las fallas de los movimientos marxistas seculares. Si bien los primeros movimientos islamistas del siglo Xx no fueron movimientos armados, una vez que se enfrentaron a la estructura militar, policial y de inteligencia del Estado secular fueron perfilando sus estrategias armadas en el mismo grado que su interlocutor, y con ello agudizaron sus posturas ideológicas contra sus opresores, sobre todo cuando los líderes intelectuales de los movimientos fueron encarcelados y obligados a mantener correspondencia con sus aliados por canales clandestinos que, inevitablemente, los llevaron a radicalizar su discurso.

No obstante lo anterior, cabe decir que la fortaleza de las acciones contenciosas del islam político radicó ante todo en un discurso que se proclamó por encima del sistema de clases, que asignó un carácter moral a la restructuración de las relaciones de poder político, que criticó el modelo secular tanto en el poder como en la oposición, y que pudo llegar por igual a universitarios y a analfabetos, a hombres y a mujeres, a musulmanes y a no musulmanes, a árabes y a no árabes gracias al uso extendido de la cultura popular islamicada que compartía la mayoría de la sociedad, y romper con la hegemonía del Estado en la educación, la prensa y el espacio público. Sin afán de crear una apología del momento, vale la pena rescatar algunos hechos que ayuden a entender la fortaleza del islam político como herramienta contrahegemónica, justo para comprender por qué en pleno siglo XxI, a pesar de algunas teorías que hablan de una etapa postislamista (Bayat, 2013), los movimientos del islam político conservan aún cierta fortaleza en la política de Medio Oriente y, con todo y contradicciones, errores, actos 
de corrupción, éxitos y fracasos, siguen siendo un actor fundamental en la dinámica de los conflictos de la región.

\section{La acción contenciosa del islamismo egipcio antes de la derrota de 1967}

En octubre de 1954, Mahmoud Abdel Latif, miembro de la Hermandad Musulmana, fue acusado de asesinar al presidente Nasser. La severa reacción del Estado se sumó a las fricciones cuando la Hermandad Musulmana acusó a Nasser de "vender Egipto a Occidente" tras la extensión del tratado anglo-egipcio de 1936. Esto evidenció que los discursos anticolonialistas de la región se habían articulado con las narrativas islamistas, y que en países como Egipto habían producido bases sociales tan diversas y complejas como las de la misma Hermandad $\mathrm{Mu}-$ sulmana, la cual contaba con perfiles que iban desde tecnócratas, estudiantes y profesores universitarios, sectores de la clase obrera que se habían visto forzados a migrar del campo a las ciudades, hasta egipcios pro palestinos y antisionistas molestos por lo sucedido en la crisis de 1948, y, sobre todo, una amplia gama de desempleados por la fuerte crisis económica y social por la que atravesaba el país. ${ }^{14}$

Con lo anterior se argumenta que la movilización islamista y la de sus intelectuales no fue sólo una reacción a la represión nasserista, sino también un ejemplo de acción contenciosa que diseñó estrategias contrahegemónicas y críticas contra las decisiones económicas, políticas y militares del aparato gubernamental egipcio, argumento que se sostiene a partir de tres evidencias concretas.

El primer ejemplo se encuentra en el impacto del texto $A l$ Halal wal Haram fil islam [Lo lícito y lo prohibido en el islam], del influyente intelectual egipcio Yusuf al Qaradawi, en

${ }^{14}$ El avance de la Hermandad llevó al asesinato de uno de sus principales líderes, Hassan al Banna, en 1949, y ante la llegada de Nasser, después de un momento de encuentros y desencuentros con los Oficiales Libres, a una persecución que pondría en prisión a otro gran cabecilla, Sayed Qutub, en 1954. Estos hechos llevaron a una criminalización de la organización que ya comenzaba a operar en varios países de la zona con una mezcla de discurso islamista y otro de corte antisecular y antisionista. Véase Qadi Zadeh, 2006, p. 38. 
El Cairo en 1960, ${ }^{15}$ texto que, de acuerdo con Waleed Saleh, se usó para referirse a los años cincuenta y sesenta como una coyuntura en la que la difusión de opiniones contra el islam se había extendido gracias a gobiernos que este intelectual consideraba como "corruptos y apóstatas", "destinados al fracaso por el hecho de provenir de círculos ajenos a la cultura islámica” (Saleh, 2006, p. 46). Con Al Qaradawi se extendió “el pensamiento del rechazo a las ideas occidentales”, en consonancia con las tesis que circulaban en Irán y otros países al respecto (Ahmad, 1962), sobre todo por las formas en que la tortura y la persecución eran utilizadas contra organizaciones que el gobierno consideraba clandestinas, entre ellas la propia Hermandad Musulmana, a la que este intelectual pertenecía desde 1942. Con este tipo de ideas se graduaron nuevos liderazgos, entre los que había personajes que deseaban la muerte de Nasser por su postura no sólo contra la Hermandad Musulmana, sino también contra todo movimiento islamista que no apoyara al régimen, como Ali Asmawi, Ahmad Abdel Mayid, Abdel Fatah Ismail, Hasan al Hadibi, Omar Abdel Rahman (este último tuvo una gran influencia en movimientos violentos como $\mathrm{Al}$ Yama' al islamiyya), entre otros. Yusuf al Qaradawi fue encarcelado entre 1954 y 1956 y, posteriormente, en 1962, hasta que fue desterrado a Qatar, donde vive al tiempo de escribir estas líneas.

Un segundo ejemplo de acción contenciosa se encuentra en los debates universitarios. A pesar del gran programa lanzado por Nasser, conocido como Ta'wiya [resocialización], las universidades sirvieron como espacios interdiscursivos para el debate no sólo de ideas nacionalistas y marxistas, sino también de múltiples narrativas islamistas. Es sabido que si bien Nasser utilizó a los grupos estudiantiles islamistas para encauzar

${ }^{15}$ Yusuf al Qaradawi fue un estudiante sobresaliente en la prestigiosa Universidad de Al Azhar. Admirador de Hassan al Banna y de fuertes sentimientos anticoloniales y antisionistas, trabajó y publicó en Egipto a lo largo de los años cincuenta, y después de 1962 en Qatar, donde vive actualmente y trabaja para el canal árabe Al Jazeera. A pesar de haber estudiado en Egipto y vivido la mayor parte de sus años en Qatar, sus hijos estudian en Estados Unidos y Europa, y ha tenido influencia de pensadores occidentales a lo largo de su carrera. Véanse más detalles, críticas y reflexiones de su vida y su obra, en Kurzman, 1998, p. 340. Una de sus obras más influyentes es Al Qaradawi, 1993, p. 662. 
sus ideales en contra de organismos marxistas en los campus universitarios, esto no fue del todo exitoso porque no evitó el semillero de líderes que se cultivó en esos años y que después encabezaría grandes movimientos islamistas tras la derrota de 1967. El periodo que abarcó de 1954 a 1967 fue uno de siembra de intelectuales islamistas, cuya producción entró en proceso de madurez mientras Nasser repartía esfuerzos y recursos en frentes tan diversos como su posicionamiento en el Movimiento de Países No Alineados, la represión a los marxistas del Movimiento Comunista Egipcio y al intento de golpe del general Nayib, la crisis de Suez de 1956 y sus aspiraciones panarabistas mediante el impulso de la República Árabe Unida.

Las universidades de El Cairo y Al Azhar fueron los lugares más utilizados por los estudiantes islamistas, al grado de que para 1961 el gobierno egipcio aprobó una ley que cedía al Estado el control directo de la mezquita-universidad de Al Azhar, situación que permanece hasta la fecha. ${ }^{16}$ Algunos intelectuales que estudiaron en este periodo ingenierías, ciencias sociales, medicina e historia, entre otras carreras, son Omar Abdel-Rahman, Ala Mohieddin, Adel Hussain, Karam Zuhdi, Mohammed al-Zawahiri, Muhammad 'Abd al-Salam Farraj, Ahmed Subhy Mansour, Naabil al Ba'ari, Talal al Ansari, Ismail Tantawi y Ayman al Zawahiri, entre otros (Saleh, 2006, p. 53).

Sobra decir que estos tiempos coincidieron con la expansión de la Hermandad Musulmana a países como Libia, Iraq, Jordania, Siria y Sudán, y su conexión con otras organizaciones islamistas similares en sus objetivos como Al Ulama al islamiya (en Líbano y Argelia), Al Yama'a al Ulama (en India) y Yama' al islamiya (en Pakistán), y con líderes islamistas en Irán, como se verá más adelante. En el espacio público universitario, Walid M. Abdelnasser (2011, p. 57) argumenta:

Sayed Qutub mantuvo contacto no sólo con organizaciones islamistas egipcias y extranjeras, sino también con mandatarios del mundo árabe, tal como fue el caso del iraquí Abdul Salam Arif, a quien siempre agradeció por haber mediado en su liberación de la cárcel en 1964.

${ }^{16}$ Helwan también lo fue, pero desde 1975, aunque en 1969 hubo algunas movilizaciones en varios de sus institutos de investigación científica. 
Una tercera evidencia radica en las acciones realizadas dentro de las prisiones, particularmente el caso del encarcelamiento de Sayed Qutub. Cuando fue enviado a la cárcel de nuevo en 1965, algunas fuentes señalan que el grupo alrededor de Qutub creó un sistema de comunicación tan sofisticado que permitió la interacción no sólo entre los miembros que se encontraban dentro con los que estaban fuera de prisión, sino también con los que se encontraban fuera del país (Zollner, 2011, pp. 41-43). Al respecto, las memorias de Zaynab al-Ghazali (1974) mencionan el papel fundamental que desempeñaron las mujeres, esposas y hermanas de los miembros de la Hermandad para mantener dicha comunicación en el marco de una organización que se conoce como las Hermanas Musulmanas, aunque su nombre es más conocido en lengua árabe como Al Sayyida al Muslimat. Otro ejemplo lo constituyó el grupo liderado por Sukri Mustafa, de nombre Yamaa'al Muslimin (después conocido como Takfir wal Hiyra), quien fuera compañero de Qutub en la prisión de $\mathrm{Abu} \mathrm{Zabal}$ ya hacia finales de los años sesenta.

La visión islamista de grupos ajenos a la Hermandad Musulmana asignó un carácter moral a la restructuración de las instituciones y de las relaciones de poder en el mundo árabe. Como evidencias de este argumento, Fuad Ajami cita la forma en que diversos discursos islamistas fueron promulgados por una gama muy amplia de actores tanto del islam oficial como del islam popular, entre ellos el rey Faisal (con el que Nasser tuvo un enfrentamiento a raíz del conflicto en Yemen), el rey de Marruecos Hassan II, el islamismo del Frente Islámico Nacional de Hasan al-Turabi (intelectual sudanés que se doctoró en La Sorbonne y que fue un pilar de la revolución de 1964 de su país) e incluso el del intelectual libanés Muhammad Izzat Nasr Allah, quien ya desde 1969 había propuesto "revivir el califato islámico y entregárselo al rey saudí para que se convirtiera en el nuevo califa", todo esto sin mencionar las expresiones islamistas en Turquía, Pakistán, Irán o los movimientos sufíes en Argelia (Nasr Allah, 1970, pp. 207-209). ${ }^{17}$

${ }^{17}$ Otros casos que apuntalan el revivalismo islámico de finales de los años sesenta se encuentran en el texto $A l M u^{\prime}$ 'amarah wa Mu'arakat al Masir [La conspiración y la batalla del destino], cuyo autor, Sa'ad Jumah, cita el advenimiento del islam político tan pronto como se sabe de la derrota contra Israel, cuando Nasser envía un cable 
El punto destacable es que la radicalización de las ideas islamistas que pugnaban por un Estado islámico y una islamización de la cultura en Egipto no se debió a la derrota árabe de 1967, como muchos intelectuales suelen narrar, ni a una reacción ante la derrota de Nasser, sino que se entiende mejor si se estudia como un proceso simultáneo a la represión que el gobierno egipcio implementó contra los intelectuales islamistas en medio de un contexto en el que el islamismo no era tan ajeno en la región.

De hecho, al menos en Egipto, las ideas del islamismo se fortalecieron contenciosamente dentro de las prisiones a lo largo de los años cincuenta y sesenta, en particular durante el periodo del encarcelamiento de Qutub y de muchos de sus colegas, y no en las primeras planas de los periódicos nacionales o internacionales que anunciaron la derrota de Nasser después de 1967. Si bien los resultados de la guerra de los Seis Días pusieron las condiciones para ampliar el mensaje de los islamistas (como ciertamente ocurrió), hay que decir que los componentes ideacionales clave de las movilizaciones de los años setenta se construyeron en las redes informales y clandestinas del periodo anterior. Además, si uno pone atención a los escritos de Qutub y compara aquellos producidos durante su vida intelectual previa a su encarcelamiento con los redactados después de la privación de su libertad, encontrará una transformación notable entre los textos que tratan de la importancia de reformar el islam como entidad política y social, y los que hablan de las esferas de la inquietud y el llamamiento al activismo y al compromiso político para oponerse al sistema y pedir el (re)establecimiento de un gobierno islámico (Zollner, 2012, pp. 51-53).

al rey Hussein de Jordania y da su consentimiento para el retiro de tropas jordanas de la ribera occidental con una dosis muy fuerte de religiosidad (realmente atípica en los discursos de Nasser): "Creemos en Alá y no es posible que nos abandone, y quizá en los días venideros Él nos dé la victoria”. Un caso más fue la cólera que causó la publicación de la revista oficial de las fuerzas armadas sirias Yeish $A s h a^{\prime} b$, a unas semanas de que estallara la guerra del 67, donde se sataniza la religión musulmana. La molestia de los sirios fue tal que se obligó al gobierno sirio a disociarse de tales afirmaciones y a corroborar el peso del islam en buena parte de la sociedad siria. Véase Ajami, 1981, p. 129. 


\section{La acción contenciosa en Irán antes de 1979}

Otro escenario que presentó elementos similares a los que estaban ocurriendo en Egipto fue el islamismo iraní, el cual produjo sus propias acciones contenciosas para debilitar al gobierno del shab Mohammed Reza Pahlevi y construir un proyecto que tuvo consecuencias geopolíticas muy grandes en la región después de la instauración de la República Islámica de Irán.

De hecho, las evidencias que se tienen para hablar del islamismo contencioso en Irán datan de la misma época en la que se discutieron estas ideas en Egipto, al grado de que se tiene documentada parte de la comunicación entre la Hermandad Musulmana y algunos líderes islamistas iraníes al menos desde la década de 1950.

Aunque había elementos en común, también hubo grandes diferencias. Una de las razones que posibilitó el diálogo entre la Hermandad egipcia y los islamistas iraníes fue la difamación que los intelectuales islamistas de ambos países experimentaron por parte del gobierno wahabí de Arabia Saudí, que afirmaba que "cualquier interpretación del islam que estuviera fuera de la certificación wahabí no podía ser considerada islámica” (Kurzman, 2002, p. 158). Entre los datos más documentados de esta comunicación se encuentra la correspondencia que mantuvo Navab Safavi (polémico líder fundador del movimiento Fedai'yan-e islam) con el mismo Sayyed Qutub. De acuerdo con Yusuf Qadi Zadeh (2011):

Safavi fue quien discutió las ideas de la Hermandad Musulmana directamente con Jomeini en Qom durante algunos años, pero su ideología varió entre una postura nacionalista, islamista e incluso pro occidental, lo que provocó su pérdida de legitimidad política ante egipcios e iraníes.

No obstante lo anterior, luego del golpe de 1953 en Irán, es sabido que Safavi apoyó a los británicos y su organización quedó señalada como la responsable de asesinatos de notables figuras e intelectuales como el historiador Ahmad Kasravi. Sin embargo, el historiador iraní Ervand Abrahamian (2013, p. 253) documenta que la labor de Safavi en el contexto de los años cincuenta no era exclusiva de su grupo, pues la misma Hermandad Musulmana también recibió ofertas del general 
Glubb, comandante británico de la Legión Árabe en Jordania, para colaborar a favor de Londres en Irán a cambio de influencia británica para ellos en El Cairo.

Otra evidencia del contacto ideológico entre estos grupos se encuentra en la traducción del pensamiento de Sayyid Qutub por parte de Ali Jamenei a través de diversos textos como $\mathrm{Al}$ Mustaqbal le Haza al-Din [El futuro de esta religión], Tafsir-o fi Zelal Al-Qur'an [Tafsir sobre la obra En la sombra del Corán] y otras 10 obras del pensador egipcio que se tradujeron después de 1979 (Khaliji, 2009). No obstante, si bien la Hermandad fue uno de los primeros grupos que felicitó a Jomeini por su triunfo en 1979 al compartir posturas antisionistas y antiimperialistas, la relación entre ellos se fue haciendo cada vez más fría debido a que el modelo de Jomeini presentó algunos desafíos a la propia organización, así como a organizaciones islamistas de la región, sobre todo cuando, en medio de la guerra Irán-Iraq, habría de ser la Siria de Hafez al Assad (y no la Hermandad egipcia) el único actor que respaldaría a Irán en dicha guerra, a pesar de las claras diferencias ideológicas entre el Baa'th sirio y el Velayat al Faqih iraní. ${ }^{18}$

Las primeras acciones contenciosas islamistas en Irán se hicieron a través de panfletos, cintas de radio y revistas clandestinas como Combatiente (Moyahed), que era nutrida por grupos islamomarxistas y familias bazaríes simpatizantes de Jomeini. Entre 1962 y 1979 comenzó a visibilizarse en Irán un potente movimiento político que fue apoyado por la mayoría de las masas, liderado desde el exilio por el ayatola Jomeini y apuntalado por las ideas de grandes intelectuales (algunos simpatizantes de las guerrillas inspiradas en las estrategias contenciosas directas de la Revolución cubana o la guerra de Independencia de Argelia), con el cual se llamó al derrocamiento del shab al prometer una "regeneración de carácter moral y una verdadera independencia de los recursos nacionales del país" (Garduño, 2016, p. 108).

La acción contenciosa de los intelectuales iraníes se nutrió de tesis como las de Ahmed Fardid, pero internacionalizadas

${ }^{18}$ Éste sería el inicio de la alianza entre Irán y Siria, y entre Irán y Hamás, pues algunos miembros de la Hermandad permanecieron en contacto directo con Irán, como lo prueba la publicación del texto Jomeini: la alternativa islámica, de Fathi Abdul Aziz. 
por Yalal al Ahmad cuando se publicó el texto Gharbzadegi [La plaga de Occidente], traducido a varios idiomas no sólo en Medio Oriente sino también a lo largo del sureste asiático y otras partes del mundo..$^{19}$ Las acciones islamistas se concentraron en erosionar la legitimidad y el poder simbólico del shah a través de las ideas más vanguardistas del momento y sirviendo como enlace entre la élite del bazar y las guerrillas para financiar el armamento con el que se enfrentarían a las fuerzas de seguridad del shah..$^{20}$

Un primer ejemplo de lo anterior fue la influencia de la obra Bahti dar Baray-e Marya va Rohaniyat [Una discusión sobre el Marya'a y la Rohaniya] en 1962, a raíz de la necesidad de pensar el futuro del shiismo tras la influencia del factor externo. En esta obra, compuesta por diálogos entre pensadores musulmanes e intelectuales islamistas en los seminarios (bowze) de Qom, Teherán e Isfahán entre 1960 y 1961, participaron intelectuales tan diversos en sus posturas y perspectivas como Morteza Motahari, Mahmud Taleqani y Mehdi Bazargan, entre otros. Las discusiones de estos encuentros tenían el objetivo de averiguar el papel de los seminaristas en la política nacional y explicar las diferentes posturas al respecto entre los interesados en interpretar el islam para trazar un camino que llevara al cambio social, o bien entre aquellos que preferían seguir la tradición del quietismo esperando el advenimiento del imam oculto para recibir dicho cambio (Tabatabai y Behesti, 1962, pp. 261-266)..$^{21}$

${ }^{19}$ Garbzadeĝ̀ (غربزدخى) es un término peyorativo en lengua persa que suele ser traducido como "intoxicación de Occidente" (westoxication). Se refiere a la voluntad de adoptar e imitar el modelo de la cultura occidental en la identidad cultural iraní, sobre todo en rubros como educación, arte, economía y geopolítica. La primera vez que se utilizó fue en la década de 1940, por el profesor Ahmad Fardid de la Universidad de Teherán, pero su uso se popularizó en la publicación clandestina del libro del mismo título de Yalal al Ahmad, un crítico político que militó un tiempo en el partido Tudeh y simpatizó con Mosadeq en el interregnum nacionalista contemporáneo de uno de los lingüistas más renombrados del Irán actual, Ali Akbar Dejoda, creador del diccionario de persa moderno más extenso que se conoce. Véase Axworthy, 2014, p. 78.

${ }^{20}$ Un punto de partida se ve en la muerte del ayatola Boruyerdi, en marzo de 1960, una de las fuentes de emulación (Marya' Taqlid) más importantes de Irán y del shiismo duodecimano, evento que significó el abandono del quietismo religioso en los asuntos del Estado y el impulso de una serie de discusiones sobre los asuntos políticos de coyuntura.

${ }^{21}$ Uno de los efectos de estos seminarios es que no produjeron acuerdos con- 
Otro espacio por excelencia donde se estimuló el pensamiento del modernismo religioso para criticar al shab fueron los salones de congregación (hosseyniyeh), y la Hosseyniyeh Ershad fue uno de los íconos que albergó a pensadores de la talla del ayatola Motahari, Mohammad Homayun y Ali Shariati, a quien se ha denominado "el verdadero ideólogo de la revolución" por sus innovadoras ideas (las cuales distanciaban el islam de una interpretación normativa y estrictamente coránica) al mezclar, tal como otros intelectuales lo habían hecho alrededor del mundo islámico, los conocimientos islámicos alcanzados en Mashad con los conocimientos adquiridos durante su estancia en Europa, particularmente en Francia, después de obtener un doctorado con la discusión de textos de Jean-Paul Sartre, Franz Fanon, el Che Guevara y Roger Garaudy, entre otros. ${ }^{22}$ Cabe agregar que este espacio se erigió como un activo instituto de educación e investigación desde una perspectiva crítica que enfatizó los valores nacionalistas como eje de construcción de una identidad iraní, pero tomando el islam como punto de partida para cualquier cambio social impulsado por las élites o grupos subalternos.

Aunque hubo una plétora de interpretaciones del islam en otros lugares desde la universidad, el bazar, la mezquita, jardines y casas privadas, reformistas y modernistas intercambia-

cretos a corto plazo, lo que llevó a la descentralización de la marya’ como institución, pues algunos religiosos en Iraq, Líbano e Irán se autoerigieron como tales en su respectivos seminarios o incentivaron a sus estudiantes a que hicieran lo mismo debido a la necesidad de contar con cierta legitimidad que les permitiera mantener organizadas a sus comunidades ante el vacío de poder que había dejado Boruyerdi. Cabe señalar que en las normas de la Ruhaniya, la gayba (ocultamiento) del décimo segundo imam otorga al ayatola un papel más activo en la comunidad al asumir prerrogativas solo atribuibles al mahdi, como dirigir la oración del viernes, el derecho de recolectar los impuestos y la facultad para declarar el yihad, lo cual exigía cierto reconocimiento social que se tuvo que buscar en las escuelas con más prestigio tradicional, como Nayaf y Kerbala en Iraq, lo que dejó a Qom en estado de incertidumbre política momentánea.

${ }^{22}$ Una de las principales obras de Ali Shariati fue Insan va islam [Hombre e islam], en la que abordó las vivencias en la historia del islam y los valores éticos y la conducta que marcaron sus actos. De hecho, fue a partir de su incorporación a la Hosseyniyeh Ershad, en 1969, cuando Ali Shariati surgió como líder clave que influyó en muchos movimientos revolucionarios de izquierda por algunas de sus ideas, como "el martirio es la defensa de la justicia social” y "todos los días son Ashura”, entre otras. Véase Abrahamian, 1982, pp. 24-28. 
ron puntos de vista para enfrentar las políticas económicas del shab y las persecuciones de sus servicios de inteligencia, la SAVAK, la cual, como ocurrió en Egipto, se convirtió en una organización sumamente violenta que (no sólo) expulsó a Jomeini hacia Turquía en 1964, encarceló a Shariati y cerró la Hosseyniyeh Ershad en 1972, sino que también cometió actos de tortura contra activistas comunistas, marxistas y anarquistas, como se ha documentado recientemente (Mctigue, 2012).

Las prisiones y el exilio, al igual que en el caso egipcio, fueron otro lugar por excelencia de diálogo y discusión de las producciones islamistas iraníes. Particularmente la prisión de Evin, donde islamistas como los ayatolas Mahmoud Taleqani y Hussein Ali Montazeri, e islamo marxistas como Masud Rajavi, compartieron ideales en común que después se verían reflejados en la conducta de la guerrilla iraní (Mesa, 2010, p. 451).

Lo anterior lleva a hablar de un tercer ejemplo de acción contenciosa, esto es, la formación de la misma guerrilla iraní. A lo largo de los años sesenta, diversas agrupaciones de izquierda se formaron para diseñar estrategias armadas contra la monarquía. ${ }^{23}$

De las decenas de grupos en esta escena, dos organizaciones se erigieron como las más importantes por su efectividad contra la SAVAK y la importancia de sus ideas en las universidades del país, particularmente en la Universidad de Teherán: los Fedayin-e Jalq (Fedayines del Pueblo) y los Moyahedin-e Jalq Iran (Combatientes del Pueblo de Irán). Estas dos organizaciones se encargaron de liderar los combates contra el ejército de la monarquía iraní en un momento en que la legitimidad del régimen se encontraba seriamente fracturada y cuando los movimientos islamistas en la región se fragmentaban entre aquellos que optaban por la estrategia social como vía para el cambio y los que preferían combinarla con la vía armada.

${ }^{23}$ A diferencia del caso egipcio, el contacto entre marxistas e islamistas en Irán fue constante a través de diversas tertulias con vías a la unificación e, incluso, combates coordinados contra la SAVAK y los servicios de seguridad del shah. No obstante, las diferencias ideológicas y la falta de acuerdos políticos fueron obstáculos que no permitieron una alianza directa entre ellas. De hecho, ambas facciones llegaron a enfrentarse en las calles de Teherán cuando los marxistas del grupo Fedayin-e Jalq fueron excluidos en las listas para participar en las elecciones parlamentarias organizadas por el nuevo gobierno (Abrahamian, 1989, p. 197). 
La guerrilla iraní se había formado con una combinación ideológica que los círculos más conservadores de los seminarios no aceptarían posteriormente. En principio, los Fedayin-e Jalq recibirían ayuda de algunas familias bazaríes, pero mantendrían una tendencia claramente marxista. En el caso de los Moyahedin, la combinación radicó en su enfoque "islamo-marxista", el cual defendieron diciendo que "la técnica marxista y el espíritu del islam era lo que mantenía su vitalidad para conectar con las masas del pueblo iraní y lograr juntos el derrocamiento del shah" (Garduño, 2016, p. 108). Estas organizaciones, además, establecieron conexiones con movimientos nacionalistas en el mundo árabe, como la Organización para la Liberación Palestina de Arafat, y a pesar de tener un discurso nacionalista y laico, pudieron establecer relaciones de solidaridad mediante el eje armado y la importancia de combatir la influencia occidental en sus luchas respectivas.

No obstante tanta diversidad, la meta común de éstos y otros grupos fue transmitir a la gente la importancia de formular respuestas a la tiranía del shah. Pero de esta gama ideológica, el mensaje y el carisma de Jomeini fueron los más fáciles de digerir, particularmente entre la población que residía en el sector rural y la población marginada de las grandes ciudades, como Teherán e Isfahán. Aunque Jomeini y sus asesores se nutrieron de ideas de intelectuales como Ali Shariati, Abol Hassan Bani Sadr o el ayatola Motahari para formular la idea del Velayat-e Fa$q i h$, su narrativa ante las masas se presentó como algo innovador y eficiente que lucharía contra aquello que el arabismo no había podido superar, es decir, una retórica contra el sionismo, contra la URSS, contra Estados Unidos, contra Israel, contra la corrupción y la represión, y con el lema por excelencia de la revolución iraní de 1979, que fue jna shargi, na garbi, yumburiye eslami! (“iNi Oriente, ni Occidente. República Islámica!”).

\section{El factor externo como variable de la contracción hegemónica: Egipto e Irán en retrospectiva}

Las décadas de 1960 y 1970 son el contexto fundamental para entender la crisis del Estado secular en Medio Oriente, pues 
a través de las acciones contenciosas se entiende por qué el islamismo no fue un proyecto que nació sólo como respuesta directa al fracaso de los gobiernos seculares, sino como un proceso que se fue contrayendo de manera simultánea a la del nacionalismo, el antiimperialismo, el marxismo, el antisionismo y el anticolonialismo. Sin embargo, diversos factores externos llevaron a Egipto e Irán a destinos diferentes. La intervención extranjera y otros elementos de orden regional e internacional son fundamentales para entender estos cambios y no dar por hecho que el islamismo triunfó como alternativa, porque si bien se trató del contexto donde surgieron más grupos islamistas con repertorios de movilización violenta, también fue el que atestiguó mayor represión y masacres contra ellos, al menos en el mundo árabe.

En Egipto, un primer elemento explicativo lo constituye el fortalecimiento del nacionalismo sionista, que ya tenía planes para invadir lo que denominaba "territorios hostiles". ${ }^{24}$ Egipto fue objetivo de uno de los primeros ataques preventivos de la historia del siglo xx cuya ocupación no sólo se limitó a los territorios palestinos, sino que se extendió al Sinaí y a los Altos del Golán (Shue y Rodin, 2010, p. 215). Si bien Irán también enfrentó una intervención extranjera con la guerra Irán-Iraq a principios de los años ochenta, la diferencia estribó en que Egipto era un país que no tenía petróleo y que pasó a depender directamente del crudo y el dinero saudíes (etapa conocida como la desradicalización), mientras que el nuevo gobierno iraní no sólo era autosuficiente en energía, sino que además podría exportarla por la misma vía por la que lo hacían sus vecinos árabes hostiles, es decir, el estrecho de Ormuz, con lo que garantizaba una entrada de dinero para mantener la nueva hegemonía en el Estado. Algo en lo que coinciden Egipto e Irán en este momento es que la guerra contra Israel e Iraq, respectivamente, fue utilizada para perseguir diversos

${ }^{24}$ Ya había planes para invadir, aunque Estados Unidos los vetó en 1960. Se llamó Plan Shacham y consistía en dividir Cisjordania en ocho distritos para facilitar la administración militar. Recibe el nombre del general Mishael Shacham, uno de los cofundadores (junto con Ariel Sharon) de la Unidad 101, es decir, la unidad militar encargada de las atrocidades contra decenas de aldeas durante la guerra de 1948 . Véase Pappe, 2017, pp. 19-21. 
movimientos de izquierda que querían aprovechar la circunstancia para insertarse en la nueva arena política, lo cual no fue posible debido a la represión utilizada por sus detractores (Abrahamian, 1999, p. 35).

Un segundo elemento explicativo es el pragmatismo político. Ciertamente, durante la década de 1970 Egipto y otros países experimentaron un auge de movimientos islamistas que coincidió con lo que sucedía en otros países de la región. Por ejemplo, en Túnez, Rashid Ganouchi y otros jóvenes publicaron la revista $M a^{\prime}$ arifa [Conocimiento] y formaron la organización Jamaa al islamiya [Asociación Islámica], acciones con las cuales comenzaron a involucrarse en la discusión política contra Bourgiba mediante la formación posterior del Movimiento de Tendencia Islámica. ${ }^{25}$ En el caso de Arabia Saudí, entre el 20 de noviembre y el 5 de diciembre de 1979, Yihiman al Utaybi, un hombre que declaró a su cuñado como el mahdi, tomó la Gran Mezquita de La Meca junto con tres mil de sus partidarios y reclamó el final de la dinastía Saudí y la instauración de un sistema califal (Saleh, 2006, p. 192). Otros casos donde el avance islamista fue evidente son Sudán, Líbano e incluso Malasia e Indonesia, y las minorías musulmanas en China, Asia Central, India y varios países del África subsahariana. En el caso de Siria, la Hermandad Musulmana alcanzó una influencia social importante, al grado de organizar una manifestación masiva contra Hafez al Assad en Hama, provincia que tomaron por 27 días, pero que terminó en una de las masacres más grandes de la historia del país; algunos autores cifran el número de muertos en 20000 (Fisk, 2010). En el caso palestino, la presencia islamista también se incrementó, pues, a pesar de la ocupación israelí, el número de mezquitas en Gaza y Cisjordania creció de 400 a 750 de 1967 a 1987, se fundó la Universidad Islámica de Gaza en 1978 y se crearon diversos grupos pro Hermandad Musulmana que comenzaron a ganar elecciones estudiantiles en diversas universidades, como las de Nablus y An Najah (Marín, 1999, p. 314).

${ }^{25}$ En el ámbito local, los efectos desestabilizadores de las políticas gubernamentales, las manifestaciones de 1978 y los jóvenes universitarios interesados en el lenguaje contestatario de los islamistas fueron factores que llevaron al gobierno a calificar a sus manifestantes de “jomeinistas" o "proiraníes”. Véase Moya, 2014, p. 38. 
No obstante esta expansión islamista por la región, los islamistas en Irán mostraron un alto grado de pragmatismo al recibir, antes que cualquier otro movimiento, la visita de organizaciones nacionalistas altamente populares en el Medio Oriente como Al Fatah, liderada por Yasser Arafat, que tenía vínculos con los Moyahedin-e Jalq (que más tarde serían purgados a lo largo de la década de 1980 por el mismo Jomeini). En el exterior, los islamistas iraníes recibieron ayuda directa de la URSS y Corea del Norte para librar la guerra con Iraq. En el interior, Irán comenzó a establecer nexos con el movimiento obrero (movimiento con fuerte influencia socialista en sus demandas laborales) y adoptó celebraciones ajenas a su ideología, como el Día del Trabajo, cuestión que muestra que el islamismo de la época no funcionaba como mero discurso religioso y se entendía mejor como un instrumento de movilización en plena estrategia de supervivencia política (Abrahamian, 1993, p. 60). En este caso, es necesario aclarar que los islamistas iraníes aliados a Jomeini se convirtieron en los representantes del Estado y, mediante el establecimiento de la República Islámica de Irán, siguieron constituyendo una fuerza contenciosa frente al Estado secular, aunque con el paso del tiempo la emergencia de nuevas generaciones replicaría prácticas represoras y de censura, como la monarquía Pahlevi lo había hecho en su momento.

Un tercer elemento radicó en los diferentes impactos de la política global. A principios de 1977, con una tasa de inflación de $20 \%$ y el impacto de la recesión económica global, el país del Nilo experimentó una serie de protestas conocidas como "las revueltas del pan", movilizaciones en las que varios sectores de la sociedad salieron a las calles al grito de "¿dónde está nuestro desayuno?" y contra las cuales Sadat tuvo que desplegar al ejército egipcio en las calles por primera vez desde 1952 ("Egipto culpa a los soviéticos de la actual crisis", 1977). A los 10 meses de estos disturbios, Sadat viajó a Jerusalén, donde se entrevistó con el primer ministro israelí Menachem Begin, situación que se tradujo en la firma de los Acuerdos de Camp David en 1979, en los que Egipto se convirtió, paradójicamente, en el primer país árabe que reconoció oficialmente a Israel a cambio del retiro de sus fuerzas de la península del Sinaí, lo que provocó un rechazo regional que le costó a Egipto no sólo la expulsión 
de la Liga Árabe, sino la vida misma al presidente Sadat, que fue asesinado en octubre de $1981 .^{26}$

En el caso iraní, los islamistas coordinaron el sentimiento antiisraelí muy bien y lo explotaron para fines tanto internos como externos. Además, si bien Estados Unidos, la URSS y muchos países de Europa estaban preocupados por el éxito de la Revolución de 1979 (porque se corría el riesgo de que se extendiera a las poblaciones shiitas del golfo Pérsico y de que influyera en los movimientos contestatarios de Asia Central), estos países no intervinieron directamente en Irán y crearon dos barreras para aislar la revolución. Por un lado, Washington armó a Sadam Hussein en Iraq para iniciar la mencionada guerra Irán-Iraq, la cual duró prácticamente toda la década de 1980. Y, por el otro, la URSS invadió Afganistán para apoyar al Partido Democrático Popular de Afganistán, de corte marxista, estrategia que fue respondida por las administraciones Carter y Reagan con el financiamiento de un grupo de "luchadores por la libertad" (Moyahedin afganos) que posteriormente se convertirían en la semilla del movimiento conocido hoy como los talibanes.

A lo largo de la década de 1980, ambos frentes llevaron a cabo una política de contención y crearon un choque en el este y el oeste de Irán para desgastar la energía revolucionaria y evitar que se expandiera lo que denominaban "la ideología de Jomeini, que hacía del islam iraní un intento más de liberación contra el colonialismo y el imperialismo occidental con ciertos tintes de populismo" (Abrahamian, 1993, p. 61), mezcla que le iba muy bien a una sociedad que estaba en la búsqueda de un cambio político y acostumbrada a ser guiada por líderes carismáticos.

${ }^{26}$ Esto causó la aparición de más movimientos islamistas de corte violento, lo que dio pie a una política de represión generalizada, ya con ayuda de Estados Unidos. Cuando las actividades ideológicas de estos grupos pasaron a la escena pública, un movimiento similar se experimentó en el caso de Egipto, pues tras la muerte de Nasser surgieron diversas divisiones dentro de la Hermandad Musulmana que prefirieron librar su lucha contra el nuevo gobierno de Anwar Sadat por medio de la acción directa. Entre estas organizaciones se encontraron la Yama'a al Yihad al Misriya [Grupo de la Yihad Egipcia], Al Yama'a a islamiya al Misriya [Comunidad Islámica de Egipto], la Yama'a Salih Sariyya al Misriya [Grupo Egipcio de Salih Sariyya] y la Yama'a al Takfir wal Hiyra [Grupo de Apostasía y Emigración]. Véase Cleveland, 2009, pp. 379-380. 
Todo esto ocurrió en los años ochenta, cuando Estados Unidos comenzó a salir del "síndrome de Vietnam", trauma que ocasionó que Washington se abstuviera de emprender una operación militar más en el mundo tras haber experimentado cerca de 58000 bajas y más de 150000 heridos en la selva vietnamita, además de haber hecho un penoso papel en la fallida misión de rescate de los 66 rehenes que fueron secuestrados y que permanecieron 444 días en la hoy extinta embajada estadounidense en Teherán. En aquella ocasión, en el año de 1981, el personal militar estadounidense poco pudo hacer para evitar el secuestro y tuvo que negociar cara a cara con Teherán para la posterior liberación de los rehenes. En otras palabras, tras Vietnam y la revolución iraní, en Estados Unidos había una enorme cautela a la hora de hacer operaciones militares directamente, por lo que, cuando Reagan llegó al poder, trató de salir de dicha crisis utilizando terceros gobiernos para las operaciones militares en el mundo, lo que dio origen a la época de "los contra" en Nicaragua y del apoyo a las dictaduras en toda Centroamérica, donde Estados Unidos comenzó a mostrar su musculatura militar en su zona de influencia (Dabashi, 2017, p. 79). Las alianzas con Sadam Hussein y los Moyahedin afganos son parte de este proceso que tendría otras profundas repercusiones regionales que rebasan los objetivos de este análisis.

\section{Conclusiones}

A lo largo de este texto se asentó que no había que esperar hasta el triunfo de la Revolución de Irán de 1979 para ver las manifestaciones del islam político como un proyecto alternativo a la crisis del Estado secular en Medio Oriente, pues este modelo político, en sus diversas vertientes y facetas, tomó fuerza en la región, al menos desde los años cincuenta, a través de acciones contenciosas lideradas por diversos intelectuales islamistas, influidos por técnicas de acción directa de corte anticolonial, antiimperialista y antisionista, que utilizaron espacios como las universidades, las prisiones, el espacio público y los salones de congregación para propagar su crítica y sus postulados. 
Tomando como punto de partida lo ocurrido en Egipto antes de la derrota de 1967, y en Irán antes de la Revolución de 1979, en el texto se ofrecieron evidencias de que el islamismo revolucionario no tomó sus ideas de preceptos puramente religiosos, sino de la interlocución con los regímenes que criticaba y de las técnicas guerrilleras de tipo cosmopolita que eran muy populares globalmente y que sirvieron como herramientas de crítica a la desigualdad económica y la crisis moral que se identificaba en la mayoría de la población de la región, particularmente en los sectores más desfavorecidos de Egipto e Irán.

Más que elementos reaccionarios y fundamentalistas, el islamismo en los países revisados se tornó en un proceso de cambio que tenía el objetivo de criticar al Estado secular y que, en dicho horizonte, fue altamente pragmático y flexible a otras influencias, incluso tomadas del exterior, como ocurrió en la formación de las ideas y las obras de grandes líderes como Sayyid Qutub y Ali Shariati. A esto seguirían estrategias de acción directa y el surgimiento de diversos grupos, armados y no armados, que enfrentarían a los elementos de seguridad e inteligencia de ambos países respectivamente.

A lo largo del texto se presentaron datos que evidenciaron la crisis, tanto en Egipto como en Irán, a la que se ha hecho alusión, y se mostró que, a pesar de las resonancias en el proceso, el factor externo fue vital para entender la forma en que la acción contenciosa islamista tomó vertientes diferentes en sus respectivas dinámicas geopolíticas. En Egipto, después de la guerra de 1967, los regímenes árabes que habían llegado al poder durante las décadas de 1950 y 1960 se vieron envueltos en un ambiente de desprestigio que provocó el eventual declive de sus estructuras burocráticas, seculares, populistas e ideológicas en todo Medio Oriente, lo que los llevó a la división geopolítica regional, así como a problemas internos ante la irrupción de más movimientos islamistas con perfiles de acción directa, lo que provocó una reacción inmediata de las fuerzas extranjeras para salvaguardar intereses particulares al lado del proyecto sionista israelí.

En el campo iraní, esta situación fue aprovechada por las acciones contenciosas de Jomeini, que, ante el agotamiento de 
las ideologías seculares y una vez en Irán, se presentó como el eje articulador que hacía falta para sacar a la región, a los árabes y los no árabes, de la crisis en la que se encontraba, aprovechando que ni Estados Unidos ni la URSS podían intervenir directamente en Irán y aliándose con guerrillas de corte islamomarxistas y bases del movimiento obrero para sobrevivir a las presiones geopolíticas del momento, lo que finalmente logró a pesar de la guerra con Iraq a lo largo de los ochenta.

Finalmente, con el ejercicio anterior se muestra que el ascenso del islam político en la región no fue homogéneo y que, a pesar de que la Revolución de Irán de 1979 suele ser vista como un punto de partida para entender este fenómeno, la gestación del islam político como se conoce actualmente proviene de procesos previos y de organizaciones que canalizaron de inmediato la crisis de Nasser, sobre todo en Egipto, como el surgimiento de diversas organizaciones e intelectuales lo demostró con el tiempo.

Posteriormente, la Revolución de Irán dio un impulso a estos movimientos y alcanzó a varios países de la región al llevar un discurso que ponía la modernización secular no sólo como el gran error de los líderes nacionalistas, sino también como la responsable del estallido de la mayor parte de los conflictos en el denominado "mundo árabe" y del que enfrentaba a los árabes con el sionismo. Todo esto lo utilizó el nuevo gobierno de Irán para purgar su base islamo-marxista con fuerza y brutalidad al acusarlos de monafequin (hipócritas) y obligarlos al exilio, donde comenzarían un nuevo ciclo de acciones contenciosas que causarían otro tipo de presiones al nuevo gobierno iraní.

\author{
Dirección institucional del autor: \\ Facultad de Ciencias Politicas y Sociales \\ Universidad Nacional Autónoma de México \\ Circuito Mario de la Cueva s/n \\ Ciudad Universitaria \\ 04510 Coyoacán, Ciudad de México
}




\section{Referencias}

Abdelnasser, W. M. (2011). The Islamic movement in Egypt: Perceptions of international relations, 1967-1981. Nueva York, NY: Routledge.

Abrahamian, E. (1982). Ali Shari'ati: Ideologue of the Iranian revolution. Middle East Reports, (102), 24-28. Recuperado de https://merip.org/1982/01/ali-shariati-ideologue-of-the-iranian-revolution/

Abrahamian, E. (1989). Radical Islam: The Iranian Mojahedin. Londres: I. B. Tauris.

Abrahamian, E. (1993). Khomeinism essays on the Islamic Republic. Berkeley, CA: University of California Press.

Abrahamian, E. (1999). Tortured confessions: Prisons and public recantations in modern Iran. Berkeley, CA: University of California Press.

Abrahamian, E. (2008). A bistory of modern Iran, Cambridge: Cambridge University Press.

ABraHAMiAn, E. (2013). The coup. 1953, the CIA and the roots of modern U.S.-Iranian relations. Londres: The New Press.

Adams, M. (1971). The Muslim (Moslem) Brotherhood: Current status in United Arab Republic. Recuperado de http://discovery.nationalarchives.gov.uk/details/r/C11022393

Ahmad, J. (1962). Gharb-zadagi: maqalah. Teherán: Azad.

Ajami, F. (1981). The Arab predicament. Arab political thought and practice since 1967. Cambridge: Cambridge University Press.

Al-GHaZAli, Z. (1974). Return of the pharaoh. Memoir in Nasir's prison. Leicester: The Islamic Foundation.

Al-QARadawi, Y. (1993). Al-Halāl Wa-'l-Harām Fi'l-Islām. Beirut: Dār at-Ta'āruf.

Amin, G. A. (1980). The modernization of poverty: A study in the political economy of growth in nine Arab countries, 1945-1970. Leiden: Brill.

AnANI, K. (2016). Inside the Muslim Brotherhood. Religion, identity, and politics. Oxford: Oxford University Press. http://dx.doi.org /10.1093/acprof:oso/9780190279738.001.0001

Axworthy, M. (2014). Revolutionary Iran: A history of the Islamic Republic. Londres: Penguin.

Azaola, B. (2008). Historia del Egipto contemporáneo. Madrid: Catarata.

BARNES, W. (3 de diciembre de 2014). Islamism's rise in Egypt wasn't just because of the 1967 war. Muftah. Recuperado de https:// muftah.org/islamism-egypt-1967-war/\#.We1yDoZrx7M 
BAyat, A. (2013). Post-Islamism: The changing many faces of political Islam. Nueva York, NY: Oxford University Press. https://dx. doi.org/10.1093/acprof:oso/9780199766062.001.0001

Boothman, D. (2012). Islam in Gramsci's journalism and Prison Notebooks: The shifting patterns of hegemony. Historical Materialism, 20(4), pp. 115-140. https://dx.doi.org/10.1163/1569206X12341268

Bowering, G. (Ed.). (2012). The Princeton encyclopedia of Islamic political thought. Princeton, NJ: Princeton University Press.

Butko, T. J. (2004). Revelation or revolution: A Gramscian approach to the rise of political Islam. British Journal of Middle Eastern Studies, 31(1), 41-62.

Buttigieg, J. A. (1987). Criticism without boundaries: Directions and crosscurrents in Postmodern critical theory. Notre Dame, IN: University of Notre Dame.

Chalcraft, J. (2016). Popular politics in the making of the modern Middle East. Cambridge: Cambridge University Press. https:// dx.doi.org/10.1017/CBO9780511843952

Chalcraft, J. y Noorani, Y. (Eds.). (2007). Counterhegemony in the colony and postcolony. Houndmills, NY: Palgrave Macmillan. https://dx.doi.org/10.1057/9780230592162

Cleveland, W. L. y Bunton, M. (2009). A history of the modern Middle East. Boulder, CO: Westview Press.

Dabashi, H. (2011). The Green Movement in Iran. Nuevo Brunswick, NJ: Transaction.

Dabashi, H. (2017). Post-orientalism: Knowledge and power in time of terror. Londres: Routledge.

De Bellaigue, C. (2013). Patriot of Persia: Muhammad Mossadegh and a tragic Anglo-American coup. Nueva York, NY: Harper Perennial.

Egipto culpa a los soviéticos de la actual crisis. (25 de enero de 1977). El País. Recuperado de https://www.elpais.com/diario/1977/01/25/internacional/222994807 850215.html

Elshahed, M. (23 de marzo de 2015). Nasr City was once Egypt's new capital, but things were wrong. Cairo Observer. Recuperado de https://cairobserver.com/post/114391196879/nasr-city-wasonce-egypts-new-capital-but-things\#.We_MZ4Zryi4

Fisk, R. (16 de septiembre de 2010). Freedom, democracy and human rights in Syria. The Independent. Recuperado de https:// www.independent.co.uk/voices/commentators/fisk/robertfisk-freedom-democracy-and-human-rights-in-syria-2080463. html

GARDUÑO, M. (2016). La articulación de intereses de los Moyāhedīn-e 
Jalq-e Iran: de la Revolución Islámica al Movimiento Verde. Estudios de Asia y África, 51(1), 105-135. http://dx.doi.org/10.24201/ eaa.v51i1.2184

Giugni, M. G., McAdam, D. y Tilly, C. (Eds.). (1998). From contention to democracy. Lanham, MD: Rowman \& Littlefield Publishers.

Gramsci, A. (2009). Pre-prison writings. (Ed. R. Bellami). Cambridge: Cambridge University Press.

Gramsci, A. (2012). Selections from the Prison Notebooks of Antonio Gramsci. (Eds. y Trads. Q. Hoare y G. Nowell-Smith). Nueva York, NY: International Publishers.

Haqqani, H. (2015). Magnificent delusions: Pakistan, the United States, and an epic history of misunderstanding. Nueva York, NY: Public Affairs.

Hodgson, M. G. S. (2009). The venture of Islam, volume 3: The gunpower empires and modern times. Chicago, $\mathrm{CH}$ : The University of Chicago Press.

Hourani, A. (2013). A history of the Arab peoples. Londres: Faber and Faber.

Huntington, S. P. (1993). The clash of civilizations? Foreign Affairs, 72(3), 22-49. Recuperado de https://www.foreignaffairs.com/ articles/united-states/1993-06-01/clash-civilizations

Kahana, E. y Suwaed, M. (2009). Historical dictionary of Middle Eastern intelligence. Lanham, MD: The Scarecrow Press.

Khaliji, M. (27 de noviembre de 2009). The dilemmas of Pan-Islamic Unity. Current Trends in Islamist Ideology, 9, 64-79. Recuperado de https://www.hudson.org/research/9859-the-dilemmas-ofpan-islamic-unity-

KuRZMAn, C. (1998). Liberal Islam: A sourcebook. Nueva York, NY: Oxford University Press.

KuRZMAn, C. (2002). Modernist Islam, 1840-1940: A sourcebook. Oxford: Oxford University Press.

LEwIS, B. (1990). The roots of Muslim rage: Why so many Muslims deeply resent the West, and why their bitterness will not easily be mollified. The Atlantic. Recuperado de https://www.theatlantic.com/magazine/archive/1990/09/the-roots-of-muslimrage/304643/

MARín, R. (1999). La alternativa religiosa frente al secularismo: origen, desarrollo y aspiraciones del fundamentalismo islámico en Palestina. Estudios de Asia y África, 34(2), 295-323. Recuperado de https://estudiosdeasiayafrica.colmex.mx/index.php/eaa/ article/view/1699/1699 
McAdam, D., Tarrow, S. y Tilly, Ch. (2008). Dynamics of contention. Cambridge: Cambridge University Press.

Mctighe, K. (21 de noviembre de 2012). Years of torture in Iran comes to light. New York Times. Recuperado http://www. nytimes.com/2012/11/22/world/middleeast/years-of-torturein-iran-comes-to-light.html

Mesa Delmonte, L. (2010). El ayatollah al-ozma Hussein-Alí Montazerí y el movimiento reformista en Irán. Estudios de Asia y África, 45(2), 451-470. Recuperado de https://estudiosdeasiayafrica. colmex.mx/index.php/eaa/article/view/1977/1977

Moya, S. (2014). El islamismo en Túnez: de la independencia al renacer salafista. San José, Costa Rica: Centro de Estudios de Medio Oriente y África del Norte.

Nasr Allah, M. I. (1970). Al-Radd ala Sadeq al Azm [Una respuesta a Sadeq al Azm]. Beirut: Bayrūt Mu'assasat Dār Filisțīn ul-Ta'līf wa-al-Tarjamah.

PAPpe, I. (2017). The biggest prison on earth: A history of the occupied territories. Londres: Oneworld Publications.

PIPES, D. (1995). There are no moderates: Dealing with fundamentalist Islam. The National Interest. Recuperado de https://nationalinterest.org/print/article/there-are-no-moderates-dealing-withfundamentalist-islam-1034

QADI ZADEH, Y. (9 de febrero de 2011). Rabet Ijuan al Muslimin va Enqelab-e Eslami. [Los nexos de la Hermandad Musulmana y la Revolución Islámica]. Tebyan. Recuperado de https://article.

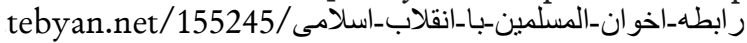

QuinTANA, S. (1984). El discurso secularista como ideología étnica: un caso del Oriente árabe. Estudios de Asia y África, 19(2), 137164. Recuperado de https://estudiosdeasiayafrica.colmex.mx/ index.php/eaa/article/view/861

Quintana, S. (1986). El integrismo islámico: una respuesta a los límites de la utopía y la crisis de las ideologías. Estudios de Asia y África, 21(1), 21-44. Recuperado de https://estudiosdeasiayafrica. colmex.mx/index.php/eaa/article/view/1034

RAFIABADI, H. N. (2007). Challenges to religions and Islam: A study of Muslim movements, personalities, issues and trends (Vol. 2). Nueva Delhi: Sarup \& Sons.

SAID, E. W. (1981). Covering Islam: How the media and the experts determine how we see the rest of the world. Nueva York, NY: Pantheon Books.

SALEH, W. (2006). El ala radical del islam. El islam político: realidady ficción. Madrid: Siglo XXI. 
SaleH, W. (2016). Librepensamiento e islam. Valencia: Tirant Humanidades.

Shue, H. y Rodin, D. (2010). Preemption: Military action and moral justification. Oxford: Oxford University Press. http://dx.doi. org/10.1093/acprof:oso/9780199233137.001.0001

Sierra Kobeh, M. de L. (2001). Democracia y procesos de liberalización politica en el Medio Oriente. México: Universidad Nacional Autónoma de México.

Sorby, K. (2004). Iraq under the reign of Faysal II (1953-1958). Asian and African Studies, 13(1), 1-27. Recuperado de http://cejsh. icm.edu.pl/cejsh/element/bwmeta1.element.84b42044-1a8230b0-88db-36a48a4ea32c? q = bwmeta1.element.7bd8eff7-fe7e35cd-847d-5b106748ea25;0\&qt = CHILDREN-STATELESS

Taвatabai, B. M. y Behesti, M. (1962). Babti dar bareh-i margi'iyat wa rubaniyat [Preocupaciones para la jerarquía jurídico-religiosa en Irán]. Teherán: Sihami.

Tarrow, S. G. (2010). The new transnational activism. Cambridge: Cambridge University Press. https://dx.doi.org/10.1017/ CBO9780511791055

TArrow, S. G. (2011). Power in movement: Social movements and contentious politics. Cambridge: Cambridge University Press.

The World Bank. (1960). Rural population 1960-2016. Recuperado de https://data.worldbank.org/indicator/SP.RUR.TOTL.ZS

Tilly, C. y Tarrow, S. G. (2015). Contentious politics. Nueva York, NY: Oxford University Press.

Waterbury, J. (2016). Egypt of Nasser and Sadat: The political economy of two regimes. Princeton, NJ: Princeton University Press.

WickHam, C. R. (2005). Mobilizing Islam: Religion, activism, and political change in Egypt. Nueva York, NY: Columbia University Press.

Zollner, B. H. E. (2011). The Muslim Brotherhood: Hasan Al-Hudaybi and ideology. Londres: Routledge. 